\title{
Experimental Auction Procedure: Impact on Valuation OF QuAlity Differentiated GoOdS
}

\author{
Jayson L. Lusk, Ty Feldkamp, And Ted C. Schroeder
}

\begin{abstract}
Despite increased use of experimental auctions, a myriad of different procedures are being employed without formal consideration of how the procedures might affect results. This study investigates the effect of several procedural issues on valuation estimates from experimental auctions. Results indicate the second price auction generates higher valuations than English, Becker-DeGroot-Marschak (BDM), and random $n$th price auctions, especially in latter bidding rounds, and that random $n$th price auction yields lower valuations than English and BDM auctions. We find that endowing subjects with a good prior to eliciting bids can have an impact on valuations, but the effect varies across auction mechanism.
\end{abstract}

Key words: BDM, endowment effect, English auction, random nth price auction, Vickrey second price auction.

In an era of rising product differentiation, where producers, processors, and retailers are attempting to "add value" to agricultural products, experimental economics are playing an increasingly important role in estimating new product premiums and targeting novel and safer foods to specific consumer segments. For example, in recent years experimental auctions have been used to estimate consumer demand for irradiated pork and chicken, non-bovine somatotropin milk, insecticide reduction in apples, steak tenderness, beef packaging, and nongenetically modified corn chips (Fox; Fox et al.; Hoffman et al.; Lusk et al. 2001a, 2001b; Roosen et al.; Shogren, List, and Hayes). Experimental methods are becoming more commonplace in nonmarket valuation because of perceived benefits relative to previously used contingent valuation survey methods. Because real products and real money are exchanged in an experimental setting, participants have more incentive to reveal their true value for a product than in a hypothetical survey setting (e.g., Cummings, Harrison, and Rutsröm; Fox et al.; List and Shogren 1998). Further, experiments place subjects in an active market en-

\footnotetext{
Jayson Lusk is associate professor, Department of Agricultural Economics, Purdue University. Ty Feldkamp is former research assistant and Ted Schroeder is professor, both in the Department of Agricultural Economics, Kansas State University.

The authors would like to thank Christy Lusk and Sean Fox for assistance in data collection and experimental design. Comments from two anonymous reviewers are also appreciated.

This research was partially funded by USDA-NRICGP grant no. 2001-35400-10557.
}

vironment, where they can learn and adjust to market conditions.

Although the use of experimental auctions has increased in recent years, applications related to product marketing, pricing, and adoption have generally been limited to the agricultural economics literature (e.g., Buzby et al.; Fox; Fox et al.; Hayes et al.; Lusk et al. 2001a, 2001b; Melton et al.; Roosen et al.; Shogren, List, and Hayes). A few studies have used experimental auctions in the marketing literature (e.g., Hoffman et al., Wertenbroch and Skiera), but applications are still rare. ${ }^{1}$ As experimental methods gain acceptance as a valuable tool in market research, the reliability and consistency of value estimates needs careful assessment.

Even a casual review of the existing literature reveals that previous experimental studies have employed a wide variety of techniques and procedures to elicit willingness-to-pay (WTP) for novel products. One of the most noticeable differences across studies is the auction mechanism used to elicit WTP. For example, the following mechanisms have been employed in the recent literature: Vickrey second price, ascending-bid second price, random $n$th price, first price, fifth price, Becker-DeGrootMarschak (BDM), English, and combinatorial private-collective auctions (Lusk et al. 2001a,

\footnotetext{
${ }^{1}$ Of course, experimental auctions are used extensively in the general economics literature, but applications mostly involve tests of economic theory rather than using valuations to make marketing or product adoption decisions.
} 
2001b; Melton et al.; Rutström; Shogren et al. 1994). Previous research also differs on how many goods are valued in a particular experimental session. Some research only valued a single product characteristic (e.g., Lusk et al. 2001b), while other studies had subjects value multiple characteristics or goods simultaneously (e.g., Roosen et al., Melton et al.). Another notable difference in previous studies is the procedure used to elicit demand for the novel product. In many studies, subjects are endowed with a good and are asked how much they would be willing to pay to exchange their endowed good for a similar good with a slightly different characteristic (e.g., Hayes et al.). In contrast, other researchers simply have subjects bid full value for a novel good (e.g., Melton et al., Rutström).

Obviously, consensus does not exist on specific procedures to employ when valuing novel products. If valuation estimates vary across different procedures, one must question the reliability of specific value estimates. Under certain assumptions, valuations will be equivalent under all the different procedures discussed above. However, it is unlikely that all the necessary assumptions will hold in practice, and previous research suggests that valuations vary by auction mechanism and procedure (e.g., Rutström). The primary purpose of this article is to determine the stability of WTP estimates across a variety of changes in experimental procedure. The need for such a study has recently been noted by Shogren et al. (2002), who in a recent summary of over a decade of lab valuation concluded (p. 21), "Subtle changes in experimental procedures... significantly impact the results... [O]ur experience leads us to conclude that over time, and as designs are refined, improved reality-based consumer experiments will become an important method for analyzing the demand side of food safety."

The goal of this article is to directly test the following assumptions typically held in experimental valuation work: $(a)$ valuations are equivalent across theoretically incentive compatible auctions, $(b)$ valuations are not reference-dependent, and $(c)$ valuations are insensitive to the number of goods being valued. Because this research focuses on eliciting "homegrown values"- those values consumers bring into an experiment-we cannot say which procedure or method elicits the most "correct" WTP estimates. However, this research can provide insight by revealing how the relative magnitudes of valuation estimates are affected by various approaches, which might improve pricing, product adoption, and policy decisions.

\section{Background}

We consider three procedural issues in experimental valuation: auction mechanism, reference-dependent preferences, and the number of goods valued. Each of these issues is important and has the potential to influence WTP estimates in a variety of ways. Previous research, especially with regard to auction mechanisms, has suggested that WTP valuations are affected by procedure, but no study has considered the breadth of procedural topics addressed here. First, a review of the literature associated with each of the issues is presented.

\section{Auction Mechanism}

One of the most important tasks in implementing an experimental auction is the decision of which mechanism to employ. The most important factor to consider in this regard is the incentive compatibility of the auction mechanism. An auction mechanism is considered theoretically incentive compatible if an individual's dominant strategy is to bid in such a manner that valuations are truthfully revealed. Even when this factor is taken into consideration, a number of options remain.

We focus on four auctions commonly used in the literature that are theoretically incentive compatible: the second price, random $n$th price, BDM, and English auctions. The structure of each of these elicitation mechanisms is outlined in table 1 . Of the auctions listed in table 1, the English auction is perhaps the most widely recognized. In an English auction, the auctioneer (experimenter) opens the auction at a relatively low price. Depending upon the setup of the auction, competitors either offer ascending bids or signal their willingness to stay in the auction as prices are increased over time. The auction ends when only one participant is willing to pay the current price. This individual wins the auction and pays the last price offered. Vickrey proposed the second price auction as a sealed-bid equivalent to the English auction. In a second price auction, competitors simultaneously submit sealed bids for a good. The individual with the highest bid wins the auction and pays the second highest bid amount for the good. Notable alternatives to the English and second price auctions are the BDM and random $n$th price auctions. 


\begin{tabular}{|c|c|c|c|c|}
\hline & \multicolumn{4}{|c|}{ Auction Institution } \\
\hline & $\begin{array}{l}\text { Second } \\
\text { Price }\end{array}$ & $\begin{array}{l}\text { Random } \\
n \text {th Price }\end{array}$ & English & $\mathrm{BDM}$ \\
\hline $\begin{array}{l}\text { Participant } \\
\text { procedure }\end{array}$ & $\begin{array}{l}\text { Simultaneously } \\
\text { submit sealed } \\
\text { bids }\end{array}$ & $\begin{array}{l}\text { Simultaneously } \\
\text { submit sealed } \\
\text { bids }\end{array}$ & $\begin{array}{l}\text { Sequentially offer } \\
\text { ascending bids }\end{array}$ & $\begin{array}{l}\text { Simultaneously } \\
\text { submit sealed } \\
\text { bids }\end{array}$ \\
\hline Winning bidder & $\begin{array}{l}\text { Participant with } \\
\text { highest bid }\end{array}$ & $\begin{array}{l}\text { All participants } \\
\text { with bid greater } \\
\text { than a randomly } \\
\text { drawn ( } n \text { th) bid }\end{array}$ & $\begin{array}{l}\text { Participant who } \\
\text { offers the last } \\
\text { bid }\end{array}$ & $\begin{array}{l}\text { All participants } \\
\text { with bid greater } \\
\text { than a randomly } \\
\text { drawn price }\end{array}$ \\
\hline Number of winners & 1 & $n-1$ & 1 & 0 to all participants \\
\hline Market price & Second highest bid & $n$th highest bid & Last bid offered & $\begin{array}{l}\text { Randomly drawn } \\
\text { price }\end{array}$ \\
\hline Market feedback? & $\begin{array}{l}\text { Yes, with multiple } \\
\text { rounds }\end{array}$ & $\begin{array}{l}\text { Yes, with multiple } \\
\text { rounds }\end{array}$ & Yes & No \\
\hline References & $\begin{array}{l}\text { Vickrey, Shogren } \\
\text { et al. (2001b) }\end{array}$ & $\begin{array}{l}\text { Shogren et al. } \\
\text { (2001b) }\end{array}$ & $\begin{array}{l}\text { Vickrey; } \\
\text { Coppinger, } \\
\text { Smith, and Titus }\end{array}$ & $\begin{array}{l}\text { Becker, DeGroot, } \\
\text { and Marschak; } \\
\text { Irwin et al. }\end{array}$ \\
\hline
\end{tabular}

Becker, DeGroot, and Marschak introduced the BDM mechanism as a way to induce individuals to truthfully reveal certainty equivalents for lotteries. In the BDM elicitation procedure, subjects individually submit sealed bids for a good. A random number or price is then drawn from a prespecified distribution. Individuals with bids greater than the randomly drawn price "win" the auction and purchase a unit of the good at the randomly drawn price. More recently, Shogren et al. (2001b) formally introduced the random $n$th price auction, which theoretically combines the best features of second price and BDM elicitation mechanisms by engaging every potential bidder and using an endogenously determined market price. In the random $n$th price auction, competitors simultaneously submit sealed bids for a good. Then one bid (the $n$th bid) is drawn from the sample of competitors. Individuals with bids greater than the $n$th bid win the auction and purchase one unit of the good at a price equal to the $n$th bid.

Formal discussions of incentive compatibility properties of the auctions are provided by Becker, DeGroot, and Marschak, Irwin et al., Shogren et al. (2001b), and Vickrey. Despite theoretical equivalence between the four auctions, empirical studies suggest behavior can diverge. Several studies have compared second price and English auction bids using induced values. Coppinger, Smith, and Titus found that bids in English and second price auctions were similar and that both auctions produced bids near theoretically predicted values. ${ }^{2}$ However, Kagel, Harstad, and Levin and Kagel and Levin found a tendency for both experienced and inexperienced participants to "overbid" in second price auctions. Second price auctions either required several repeated trials to converge to the predicted theoretical value, or never converged at all. Shogren et al. (2001b) found, in an induced value setting, that second and random $n$th price auctions were both demand revealing in aggregate, but the random $n$th (second) price auction worked better for off-margin (on-margin) bidders than the second (random $n$ th) price auction. Irwin et al. conducted an induced value study with the BDM mechanism and concluded that subjects bid consistent with the dominant demand revealing strategy.

Differences might arise between incentive compatible auctions in a homegrown value setting, where preferences are not induced, because of bidder affiliation (Milgrom and Weber). Strategic equivalence between auctions requires that rivals' valuations are independent (i.e., nonaffiliated). In homegrown value auctions, where the good is unfamiliar and information is asymmetric, this condition may not hold. Affiliation might be expected to occur in English auctions, where subjects have large amounts of public information about other individuals' valuations or in repeated

\footnotetext{
${ }^{2}$ A weakness of the Coppinger, Smith, and Titus study is that subjects were not allowed to bid greater than induced value.
} 
second or $n$th price auctions, where market prices are posted after each round (List and Shogren 1999). Of interest in this application are the behavioral differences that arise between incentive compatible auctions, when the valuation context is moved out of the induced value setting and into the arena of real, private goods, where some degree of uncertainty and affiliation can almost always be expected to exist.

A few studies have compared homegrown valuations across competing incentive compatible auctions. Rutström found that English and BDM bids were significantly lower than bids from a second price auction. In contrast, Lucking-Reiley found that revenues from English and second price auctions were not statistically different in Internet auctions. Shogren et al. (1994) did not find a statistical difference between second price and random $n$th price auction bids, but List (2003) found that random $n$th price bids were significantly greater than second price bids, especially at lower tails of the bid distribution.

Clearly, only a few studies have compared homegrown valuations across different theoretically incentive compatible auctions. Of the comparisons that have been performed, there is some disagreement. For examples, $(a)$ Rutström found second price bids were greater than English bids, but this result was not confirmed by Lucking-Reiley and (b) List (2003) found a significant difference between second price and random $n$th price, but Shogren et al. (1994) did not. To our knowledge, no previous study has compared valuations across all four auctions considered here. In the following experiment, we seek to test the following hypothesis:

$$
\begin{aligned}
\mathrm{H}_{0}: \mathrm{WTP}_{\text {second price }} & =\mathrm{WTP}_{\text {randon } n \text {th price }} \\
& =\mathrm{WTP}_{\mathrm{BDM}} \\
& =\mathrm{WTP}_{\text {English }} .
\end{aligned}
$$

Importantly, a rejection of the above hypothesis does not imply that one of the auctions is not incentive compatible. This fact can only be ascertained in an induced value setting where true values are known. What we can learn from testing the hypothesis is how we might expect valuations, and thus pricing and product adoption recommendations, to differ when alternative auction mechanisms are employed.

\section{Reference-Dependent Preferences}

Another procedural factor to consider in implementing an experimental auction is whether to endow participants with a good prior to the elicitation task. Many studies endow subjects with a good and elicit WTP to upgrade to a "higher quality" good. The advantage of the endowment is that it isolates the effect of interest and mitigates other outsidemarket influences. Fox has also argued that endowing subjects with a good forces subjects to participate and pay attention to the auction and bids they make. Some studies go so far as to impose a consumption-requirement-a requirement that subjects consume the food they end the experiment with (e.g., Fox, Hayes et al.). Further support for the endowment approach is given by Hoffman et al., who contend the most useful and reliable estimates from experimental auctions are differences in WTP between two goods. The endowment approach directly elicits this difference. As illustrated by Lusk et al. (2001b), the endowment approach can also be helpful in attracting participants in a field setting such as a grocery store. Rather than paying subjects to attend a laboratory setting, which has been shown to influence valuations (Rutström), subjects can be given a lower quality good for participation and WTP for a higher quality good can be elicited. Such an approach removes the confounding effects of necessarily high participation fees.

Despite advantages of the endowment approach, it may introduce bias in WTP estimates. Tversky and Kahneman suggest that valuations may be reference dependent. One manifestation of reference dependent valuation is that individuals might place greater value on a good if they possess it than if they do not, an effect that is thought to arise from loss aversion: where losses are valued more highly than gains.

If the reference-dependent preferences exist then value estimates for a novel product or attribute depend upon the subjects' initial reference point-whether or not they initially possess the good. We will determine whether reference-dependent preferences influence WTP in the context routinely employed in valuing novel goods and attributes. In an "Endowment" treatment, subjects will be given (endowed) one free good (good A). Subjects then bid to exchange good $A$ for another $\operatorname{good}(\operatorname{good} \mathrm{B})$. Refer to this bid as $\mathrm{WTP}_{\mathrm{AB}}$. In another "No Endowment" treatment, subjects directly bid to obtain goods $\mathrm{A}$ and $\mathrm{B}$. Refer to each of these bids as $\mathrm{WTP}_{\mathrm{A}}$ and $\mathrm{WTP}_{\mathrm{B}}$, respectively. To determine whether reference-dependent preferences exist, we test the hypothesis: 


$$
\mathrm{H}_{0}: \mathrm{WTP}_{\mathrm{AB}}=\mathrm{WTP}_{\mathrm{B}}-\mathrm{WTP}_{\mathrm{A}}
$$

If $\mathrm{WTP}_{\mathrm{AB}}<\mathrm{WTP}_{\mathrm{B}}-\mathrm{WTP}_{\mathrm{A}}$, then the subjects valued good $A$ relatively more highly when it was in their possession than when they bid to obtain it. Previous research examining differences in WTP and willingness-to-accept suggests a potential interaction between the endowment effect and elicitation mechanism (Shogren et al. 2001a; Knetsch, Tang, and Thaler). Thus, we carry out the test of above hypothesis with all four auctions previously discussed.

\section{Multiple-Good Valuation}

Previous studies differ on the number of goods subjects are asked to evaluate in an auction. Eliciting the value for only one good or attribute is clearly the most straightforward approach (e.g., Lusk et al. 2001b); however, researchers are often interested in a variety of product designs or a number of different descriptions of a product or attribute. In such cases, it becomes advantageous to have consumers evaluate multiple alternatives (e.g., Melton et al.). When conducting an experiment, there is a relatively high degree of fixed costs associated recruiting subjects and conducting an experimental session. A clear advantage of multi-good versus single-good valuation is that the researcher can get more data for little additional cost.

Despite advantages of multiple-good valuation, there are disadvantages. First and foremost, if the experimental design is not properly constructed, valuations will be affected by demand reduction or wealth effects. That is, if a subject purchases a good in one treatment of an experiment, their demand for the next good will likely fall in a subsequent treatment due to a movement along the demand curve, not necessarily due to a treatment effect. Fortunately, this problem can be easily corrected by randomly selecting a binding round or treatment, where subjects know a priori that only one good will be purchased. For example, Hayes et al. randomly selected only one of twenty bidding rounds as binding. With a random drawing determining the binding round, subjects should behave optimally in each round, so long as it is assumed that subjects' expected utility is linear in probabilities. Roosen et al. provide evidence that this assumption is not too tenuous.

Another disadvantage of multiple-good valuation is that valuation for one good may be altered by presenting the option of other available substitutes. For example, subjects may believe a guaranteed tender steak is valuable when considered in isolation but may place a different value on the guaranteed tender steak when they know a Certified Angus Beef ${ }^{\circledR}$ (CAB) steak is also available. List (2002) recently showed that valuations significantly differed depending upon whether goods were viewed in isolation or whether they were juxtaposed. Simonson and Simonson and Tversky have also shown that consumer choice can be significantly influenced by the alternatives with which a product is compared. Although neoclassical economic theory cannot account for such effects, it remains an empirical matter as to whether subjects' valuations are invariant to the number of goods auctioned. Using the notation introduced in the previous subsection, we test the following hypothesis:

$$
\begin{aligned}
& \text { (WTP } \left.\mathrm{W}_{\mathrm{A}} \text { in isolation }\right) \\
& =\left(\mathrm{WTP}_{\mathrm{A}} \text { when } \mathrm{A}\right. \text { is simultaneously } \\
& \text { auctioned with good } \mathrm{B}) .
\end{aligned}
$$

\section{Application}

Consumers were asked to evaluate several different types of beef ribeye steaks. Beef industry participants are beginning to promote programs to enhance demand through introducing information about product quality through brands or labels. However, there is uncertainty associated with which strategy should be pursued (see Lusk for a discussion of this issue). As such, we evaluate consumer preferences for several types of beef steaks that either could be used to differentiate and brand beef or are already being used to market beef. In this study, subjects were asked to evaluate five different steaks: generic, guaranteed tender, "natural," U.S. Department of Agriculture (USDA) Choice, and CAB. An information sheet was given to experiment participants that described each steak. Several studies have analyzed consumer demand for some of these types of beef steaks (e.g., Lusk et al. 2001a, 2001b; Lusk, Roosen, and Fox), but none have jointly considered all of these steak types. In the local market analyzed in this study, only the generic steak was available for sale in all grocery outlets, with Choice and CAB selling in one chain. Thus, most of these products are novel goods in that most consumers cannot purchase them in the local market. Even in cases where subjects can buy generic, Choice, 


\begin{tabular}{lllll}
\hline & \multicolumn{3}{c}{ Auction Institution } \\
\cline { 2 - 5 } Procedure & $\begin{array}{c}\text { Second } \\
\text { Price }\end{array}$ & $\begin{array}{c}\text { Random } \\
n \text {th Price }\end{array}$ & English & BDM \\
\hline Endowment-five goods & Vic-E & $N$ th-E & Eng-E & BDM-E \\
No Endowment—-five goods & Vic-NE & $N$ th-NE & Eng-NE & BDM-NE \\
No Endowment-two goods & Vic-NE2 & - & - & - \\
\hline
\end{tabular}

and $\mathrm{CAB}$, for example, there are not other alternatives available such that relative demand for each of the steaks can be directly compared. Our research design allows us to analyze demand for these novel steaks relative to preexisting substitutes.

\section{Experiment Design and Methods}

To evaluate the effect of procedural features on WTP estimates, we constructed nine experimental treatments as shown in table 2 . In the Endowment treatments, subjects were given a free $12 \mathrm{oz}$ ribeye steak that was "generic." Beyond the fact that subjects were told the generic steak was USDA federally inspected, no other guarantees were given regarding the quality of the meat. In the Endowment treatments, subjects bid to exchange their generic steak for each of the following four steaks: guaranteed tender, natural, USDA Choice, and CAB. As shown in table 2, we used the Endowment procedure in four auctions: Vickrey second price, random $n$th price, BDM, and English. These treatments are denoted Vic-E, Nth-E, BDM-E, and Eng-E, respectively.

In a second set of No Endowment treatments, subjects were not given any steak. In the No Endowment treatments, subjects directly bid on each of the five steaks: generic, guaranteed tender, natural, USDA Choice, and CAB in each of the four auctions: Vickrey second price, random $n$th price, BDM, and English. These treatments are denoted Vic-NE, NthNE, BDM-NE, and Eng-NE, respectively, as shown in table 2. Lastly, another treatment was constructed where subjects were not endowed with any good, and they only bid on the generic and guaranteed tender steaks. This is the No Endowment-two-good treatment denoted Vic-NE2.

To test the hypothesis outlined in equation (2), we calculate the differences between the generic steak bids and bids for all other steak in the No Endowment treatment. For ease of exposition, refer to the generic steak as good A, the guaranteed tender steak as good B, the natural steak as good $\mathrm{C}$, the USDA Choice steak as good $\mathrm{D}$, and the CAB steak as good $\mathrm{E}$. In the Endowment treatment, each subject was endowed with good A and we elicited WTP to exchange good A for each of other four goods, which we refer to as $\mathrm{WTP}_{\mathrm{A} i}$, where $i=\mathrm{B}, \mathrm{C}$, $D$, and E. In the other No Endowment treatment, subjects directly bid to obtain each of the five goods. We refer to each of these bids as $\mathrm{WTP}_{j}$, where $j=\mathrm{A}, \mathrm{B}, \mathrm{C}, \mathrm{D}$, and $\mathrm{E}$. To determine whether the endowment effect exists, we compare $\mathrm{WTP}_{\mathrm{A} i}$ with $\mathrm{WTP}_{j}-\mathrm{WTP}_{\mathrm{A}}$ for $j=$ $\mathrm{B}, \mathrm{C}, \mathrm{D}$, and E. ${ }^{3}$ We refer to the $\mathrm{WTP}_{j}-\mathrm{WTP}_{\mathrm{A}}$ calculations as the "implied differences" from the No Endowment treatment.

\section{Participant Recruitment}

To test the consistency of WTP across treatments, individuals were recruited from the general population of a midwestern college town using random digit dialing techniques. Subjects were offered $\$ 40$ cash to participate in a "steak preference experiment," to be conducted in the meat laboratory on the local university campus. Individuals that agreed to participate were assigned a time and date that was convenient for them. Confirmation letters were mailed to participants one week prior to the sessions to increase attendance rates. We held at least two sessions for each of the treatments outlined in table 2 and approximately twenty subjects were recruited for each session. The goal was to obtain about forty observations per treatment. Upon arriving at the session, subjects were paid $\$ 40$ cash and completed a short demographic questionnaire. Subjects were then provided an opportunity to closely examine five different beef ribeye steaks: a generic steak, a guaranteed tender

\footnotetext{
${ }^{3}$ By construction of the test, $\mathrm{WTP}_{\mathrm{A} i}$ is restricted to be nonnegative. To ensure comparability, if $\mathrm{WTP}_{i}-\mathrm{WTP}_{\mathrm{A}}$ is calculated to be less than zero, then we restrict the value to be equal to zero. Across all steaks and auctions, only $4 \%$ of differences were less than zero.
} 
steak, a natural steak, a USDA Choice steak, and a CAB steak.

Importantly, no subject was allowed to participate in more than one session. That is, all tests reported in this paper are betweensubject tests. Although there are advantages to within-subject tests, we felt that a withinsubject experiment would be too time intensive relative to the level of compensation paid to participants. ${ }^{4}$ Further, participation in an Endowment treatment, for example, would almost certainly affect behavior in a subsequent No Endowment treatment, thus drastically increasing the number of treatments required to identify an order effect in a within-subject design. The assumption in our between-subject design is that the distribution of steak preferences is equivalent across treatments. In subsequent analysis, we explicitly test and control for differences in demographics across treatments prior to drawing any conclusions.

\section{Auction Procedures}

Subjects were randomly assigned to a particular treatment. After completing the questionnaire, consumers participated in a nonhypothetical auction for several different candy bars to familiarize them with the procedures. The candy bar auctions were design to mimic the steak auctions to facilitate the learning process. Following the candy bar auction, consumers participated in an auction for the beef steaks.

The following outlines the procedures for the second price and random $n$th price auctions in the No Endowment treatments. The procedures for the Endowment treatments were identical to that outlined below except subjects bid to exchange a generic steak for the other four steaks and they necessarily took at least one steak-type home.

Step 1: Each subject simultaneously submitted five sealed bids for each of the following steaks: generic, guaranteed tender, natural, USDA Choice, and CAB.

Step 2: The allocation rule of the particular auction (see table 1) was used to determine the winning bidder(s) and the market prices for each of the steaks. The winning bidder number(s) and market prices for each of the steaks were posted in the front of the room.

\footnotetext{
${ }^{4}$ Even with our between-subject design, several experimental sessions lasted as long as ninety minutes.
}

Step 3: Steps 1 and 2 were repeated for four additional rounds. At the completion of the fifth round, one of the five rounds was randomly selected as binding.

Step 4: A random drawing commenced to determine which of the five steaks was binding.

Step 5: The winning bidder(s) of the randomly selected steak in the randomly selected round paid the market price for the steak. All other participants paid nothing and received no steak.

The procedures for the BDM mechanism were identical to that described above, except step 3 was omitted. That is, the BDM was a single-shot auction with only one bidding round. We conducted multiple bidding rounds for the second price and random $n$th price auctions because market prices were endogenously determined and subjects could incorporate market feedback into their valuations; whereas, for the BDM mechanism, market prices were exogenously determined, and as such, subjects would have received no meaningful feedback from additional rounds.

The structure of the English auction required a slight alteration in procedure. Conducting multiple rounds is redundant with the English auction because every individual openly identifies their bid during the auction. Further, it was impossible to simultaneously auction all steaks at once because of the nature of the auction. So, in the English auction we first conducted an auction for the generic steak. Once the winning bidder and market price were determined for the generic steak, we posted this information in the front of the room. Then the guaranteed tender steak was auctioned. This process continued until the winning bidder and market price were determined for each of the five steaks. That is, subjects participated in five sequential auctions: first for the generic steak, then for the guaranteed tender steak, and so on. At the completion of the five steak auctions, we randomly selected one auction to be binding. ${ }^{5}$

In each of the auctions, no individual participant had the chance to purchase more than one steak. We randomly drew the binding round in the second and random $n$th price auction to control for wealth effects. A binding steak was randomly drawn in treatments so that we could elicit demand for a single-unit (see List

\footnotetext{
${ }^{5}$ Instructions for each of the treatments are available from the authors upon request.
} 
and Lucking-Reiley for impacts of demand reduction in multiunit auctions). In each of the auctions, subjects were explicitly informed that it was in their best interest to bid exactly what each of the goods was worth to them. ${ }^{6}$

Again, it is important to note that the second and random $n$th price auctions were conducted over multiple rounds; whereas, the BDM and English were single-round auctions. Our experimental design was implemented in this manner because: $(a)$ it replicates the way most practitioners have used these auctions when valuing novel goods, $(b)$ market prices are endogenously (exogenously) determined in the second and random $n$th price (BDM) auctions and multiple bidding rounds (would not) allow subjects to incorporate market feedback into their valuations, and $(c)$ every subject openly identifies their valuation in the English, making multiple rounds with this mechanisms redundant. In subsequent analysis, we compare bids from the English and BDM to bids from all five rounds of the second and random $n$th price auctions. This approach should provide insight into relative influence of the auction mechanisms versus the impact of market feedback on valuations.

\section{Results}

Participants were recruited as a part of a larger project on consumer demand for quality differentiated beef. Response rates for the overall project were as follows: $45 \%$ of random digit dials were working numbers, $48 \%$ of contacted individuals agreed to participate in a research session, and $85 \%$ of individuals who agreed to take part in a session actually participated. One hundred and nineteen subjects participated in the No Endowment treatments with 35, 25, 22, and 27 subjects participating in the second, random $n$ th, English, and BDM auctions, respectively. Another 119 subjects participated in the Endowment treatments with 31, 29, 31, and 28 subjects participating in the second, random $n$ th, English, and BDM auctions, respectively. Lastly, another twenty subjects participated in a No Endowment treatment where only two goods were valued. Thus, a total of 258 individuals participated in the experiments reported in this article.

\footnotetext{
${ }^{6}$ Informing subjects of the dominant strategy in homegrown value auctions follows "best practices" (e.g., Rutström). More importantly, we were interested in determining whether valuations were consistent across auctions even when subjects were informed of the dominant strategy, as they would be in most applications.
}

\section{Summary Statistics}

Summary statistics for selected demographic variables are reported in table 3 . Females comprised about half the sample and the average age in each treatment was about thirty-five years. Most subjects were either highly educated or were full time students. The relatively high education rate and student participation is reflective of the population in the university town. Although the sample is not representative of the national population, we are interested in the relative behavior of participants across treatment. In that regard, we are concerned with whether the sample makeups of each treatment are similar. For each of the demographics reported in table 3 , results of ANOVA tests could not reject the hypothesis that each of the demographics were equivalent across treatment. As such, differences in demographics are not likely driving differences in behavior across treatment.

Auction bids segregated by experimental treatment and steak type are reported in tables 4 and 5. Table 4 reports bids from the first round of the second and random $n$th price auctions; whereas, table 5 reports bids from the fifth round of the second and random $n$th price auctions. Because the English and BDM were single-round auctions, valuations associated with these elicitation mechanisms are equivalent in both tables. In the No Endowment treatment (table 4), subjects were willing to pay an average of $\$ 2.46$ for a $12 \mathrm{oz}$ generic steak and $\$ 3.97$ for a $12 \mathrm{oz} C A B$ steak, for example, in the first round of the second price auction. Data in table 5 show that these statistics increased to $\$ 3.66$ and $\$ 5.17$, respectively, by round five in the second price auction. Casual comparison of bids across auctions in the No Endowment treatment suggests that second price auction bids were roughly similar to the other mechanisms in round one (table 4), but were generally greater than bids in the other three auctions by round five (table 5). A similar trend is apparent in the Endowment treatment as well-second price bids were greater than random $n$ th, English, and BDM bids, especially by round five.

Table 4 also reports implied differences from the No Endowment treatment, which can be directly compared with bids from the Endowment treatment. These statistics were calculated by subtracting the bid for the generic steak from the bids for each of the other four steaks. For the second price auction, the average implied differences are less than the 


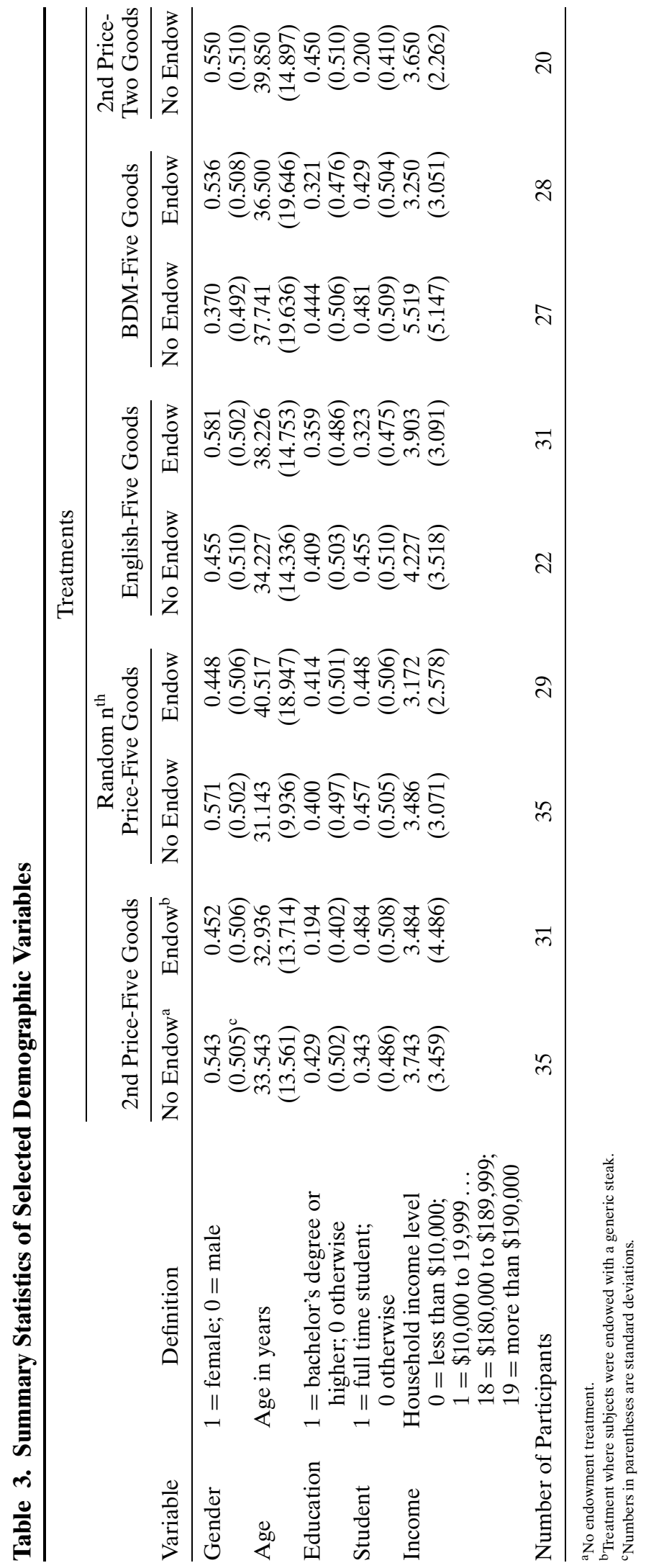




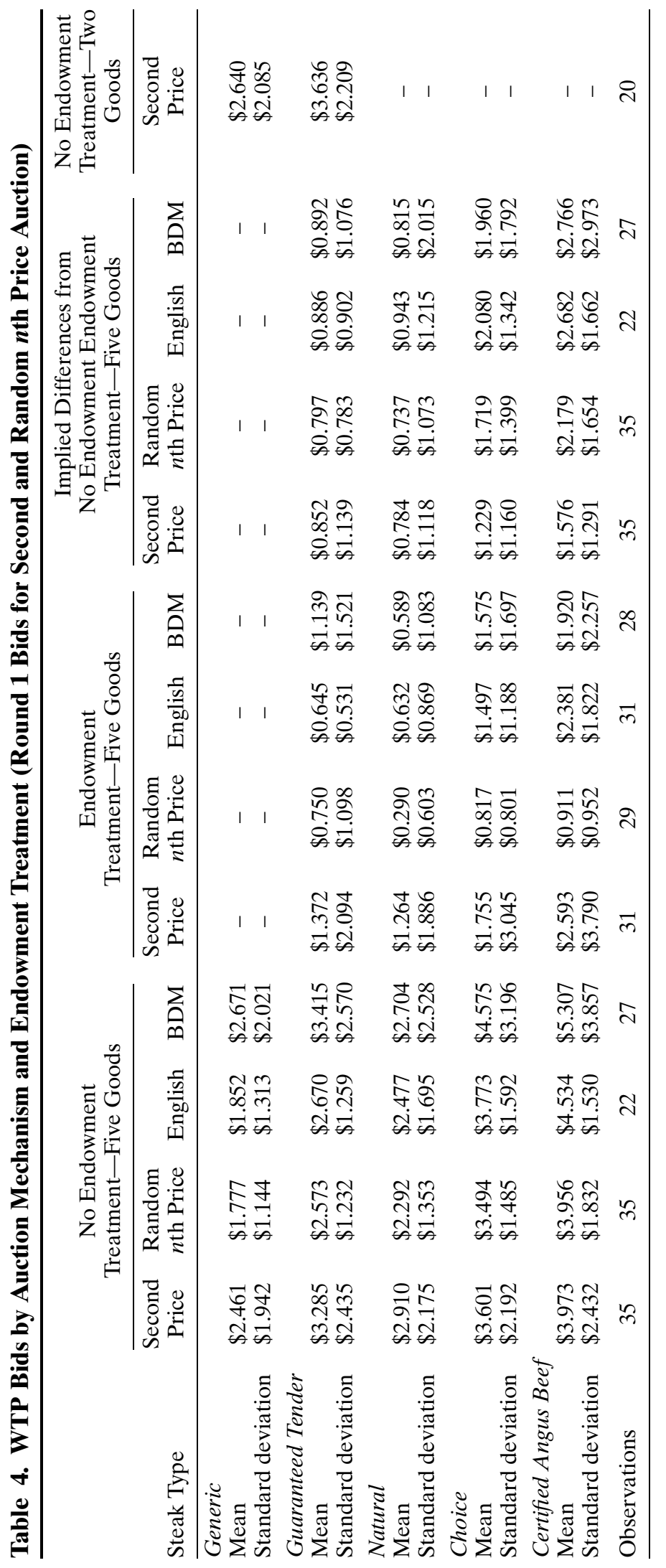




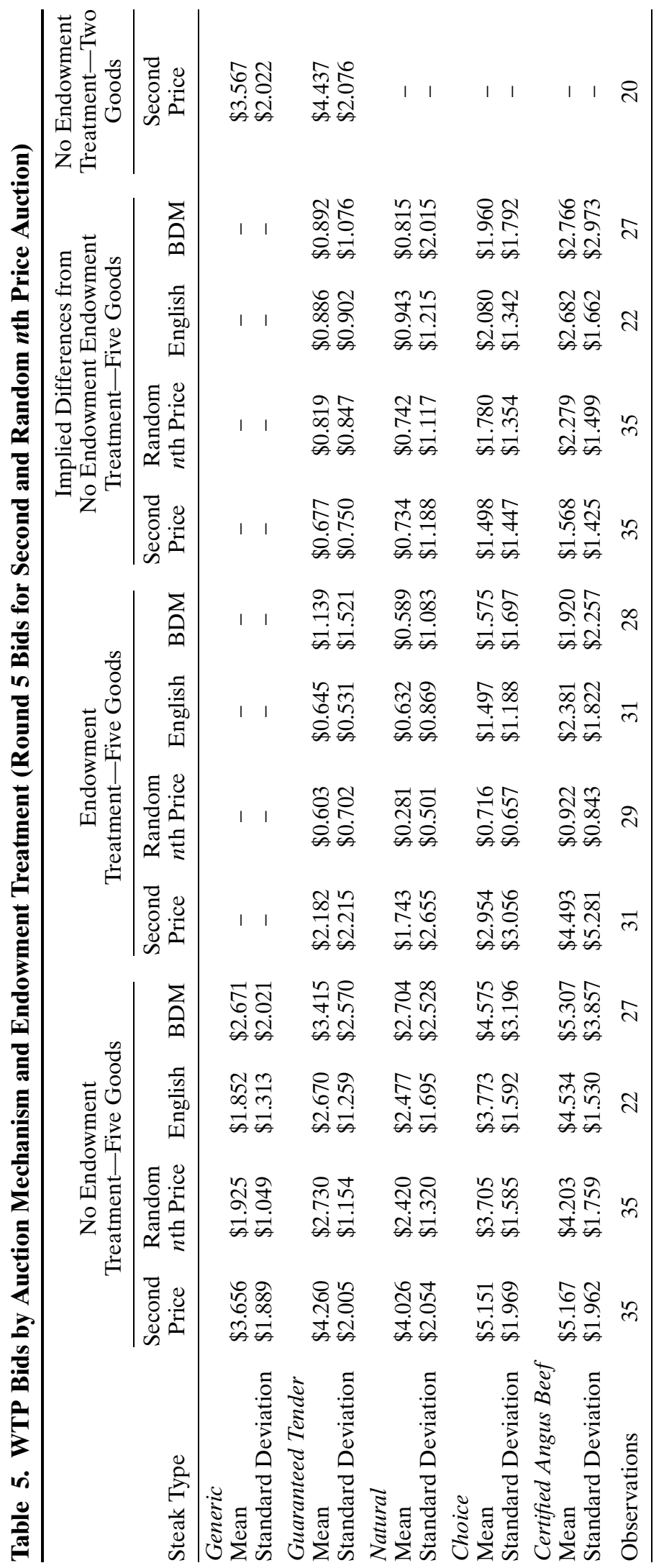


average exchange bids for each of the steaks, but the opposite is generally the case for the other three auctions. The last columns in tables 4 and 5 report bids from the second price auction where only the generic and guaranteed tender steaks were auctioned. Comparing these averages with those in the first column suggest little difference in bids when two versus five goods were auctioned.

\section{Effect of Auction Institution}

To determine whether the auction institution significantly influenced bids, we estimated three random effects tobit models as shown in table 6. We estimate tobit models because of the mass of bids located at $\$ 0.00$. The tobit models were adjusted to incorporate random effects to account for the panel nature of the data - that is, each individual submitted multiple bids for different steaks in multiple biding rounds. The tobit model, incorporating random effects is

$$
\begin{aligned}
\operatorname{bid}_{i t j} & =\alpha^{\prime} \boldsymbol{x}_{i t j}+v_{i t j}+u_{i}, \\
\operatorname{bid}_{i t} & =\max \left[0, \operatorname{bid}_{i t j}^{*}\right]
\end{aligned}
$$

where $\operatorname{bid}_{i t}$ is the auction bid for the $i$ th consumer and the $t$ th steak type (generic, guaranteed tender, etc.) in the $j$ th bidding round, which is observed only at positive levels, $\boldsymbol{x}_{i t}$ is a vector of independent variables including dummy variables identifying steak-type, dummy variables identifying elicitation mechanism by bidding round, and demographics, $\alpha$ is a conformable vector of coefficients, $u_{i}$ is an individual specific disturbance for subject $i$, and $v_{i t}$ is the overall error term (see Greene for further discussion on the random effects tobit).

The first column in table 6 reports results of a model estimated with the No Endowment data. Results indicate that consumers significantly differentiated amongst different steak types, with the CAB steak being the most desirable and the natural steak being the least desirable next to the generic steak. ${ }^{7}$ The primary results of interest are with regard to the dummy variables identifying auction type. Results indicate that bids from the English, BDM, and

\footnotetext{
${ }^{7}$ We do not make any formal attempt to explain why the CAB steak was the most preferred, whereas the natural and generic were least preferred. The fact that $\mathrm{CAB}$ was most desirable may be attributable to heavy advertising at the local level, whereas the relative undesirability of the natural steak may reflect the agrarian background of the locale.
}

all four rounds of the random $n$th price auctions were significantly less than round $5 \mathrm{sec}-$ ond price auction bids. In contrast, further statistical analysis indicates that round $1 \mathrm{sec}-$ ond price auction bids were not statistically different than English, BDM, and $n$th price bids. We also find that bids were not significantly different across the English and BDM auctions. Bids were relatively stable across the five bidding rounds for the random $n$th price auction, but bids significantly increased from round 1 to round 5 in the second price auction, with the largest change occurring between rounds 1 and 2.

Table 6 reports similar models for the Endowment treatment data. BDM and English bids were not statistically different than firstround second price auction bids, but were statistically different than second price auction bids in rounds $2-5$. For the Endowment treatment, random $n$th price bids, regardless of round, were significantly less than bids from the English, BDM, and all five rounds of the second price auction. As was the case for the No Endowment treatment, the English and BDM yielded statistically equivalent results in the Endowment treatment. Again, bids were relatively stable across the five bidding rounds for the random $n$th price auction, but bids significantly increased from round 1 to round 5 in the second price auction, with the largest change occurring between rounds 1 and 2 .

The remaining results in table 6 pertain to the test of whether auction mechanism influenced bids for the implied differences calculated from the No Endowment treatment. Surprisingly, auction mechanism had much less influence on the differences in bids. Although the second price auction tended to generate higher bids relative to the other incentive compatible auctions, the degree of inflation induced by the second price auction is roughly consistent across steaks. As a result, when differences between bids for steaks are calculated, the inflation is removed. In fact, random $n$th price auction bid differences were actually significantly greater than the round 5 second price auction bid differences. Overall, results in table 6 indicate that the auction mechanism can have substantive influence on bids. This is especially true for the random $n$th price auction and in latter bidding rounds of the second price auction. That is, the second price auction yielded similar results to the BDM and English in the first round of bidding, but response to posted market prices generated second price 
Table 6. Effect of Auction Institution on WTP: Random Effects Tobit Estimates

\begin{tabular}{|c|c|c|c|}
\hline \multirow[b]{2}{*}{ Variable } & \multicolumn{3}{|c|}{ Model } \\
\hline & $\begin{array}{l}\text { No Endowment } \\
\text { Treatment }\end{array}$ & $\begin{array}{l}\text { Endowment } \\
\text { Treatment }\end{array}$ & $\begin{array}{c}\text { Implied } \\
\text { Differences }\end{array}$ \\
\hline Constant & $\begin{array}{r}4.348^{* *} \\
(0.164)^{\mathrm{a}}\end{array}$ & $\begin{array}{r}1.147^{*} \\
(0.565)\end{array}$ & $\begin{array}{l}0.874^{* *} \\
(0.182)\end{array}$ \\
\hline Guaranteed tender & $\begin{array}{l}0.840^{* *} \\
(0.081)\end{array}$ & - & - \\
\hline Natural & $\begin{array}{r}0.457^{*} \\
(0.081)\end{array}$ & $\begin{array}{c}-0.992^{* *} \\
(0.173)\end{array}$ & $\begin{array}{c}-0.264^{* *} \\
(0.080)\end{array}$ \\
\hline Choice & $\begin{array}{l}1.679^{* *} \\
(0.081)\end{array}$ & $\begin{array}{l}0.557^{* *} \\
(0.163)\end{array}$ & $\begin{array}{l}0.963^{* *} \\
(0.075)\end{array}$ \\
\hline $\mathrm{CAB}$ & $\begin{array}{l}2.094^{* *} \\
(0.081)\end{array}$ & $\begin{array}{l}1.350^{* *} \\
(0.162)\end{array}$ & $\begin{array}{l}1.419^{* *} \\
(0.075)\end{array}$ \\
\hline English & $\begin{array}{l}-1.141^{* *} \\
(0.266)\end{array}$ & $\begin{array}{r}-1.053^{*} \\
(0.453)\end{array}$ & $\begin{array}{c}0.371 \\
(0.502)\end{array}$ \\
\hline $\mathrm{BDM}$ & $\begin{array}{c}-0.551 \\
(0.358)\end{array}$ & $\begin{array}{l}-1.280^{* *} \\
(0.493)\end{array}$ & $\begin{array}{c}0.262 \\
(0.286)\end{array}$ \\
\hline Random $n$ th-round 1 & $\begin{array}{c}-1.225^{* *} \\
(0.131)\end{array}$ & $\begin{array}{c}-1.905^{* *} \\
(0.351)\end{array}$ & $\begin{array}{l}0.331^{* *} \\
(0.140)\end{array}$ \\
\hline Random $n$ th-round 2 & $\begin{array}{c}-0.997^{* *} \\
(0.131)\end{array}$ & $\begin{array}{c}-2.148^{* *} \\
(0.351)\end{array}$ & $\begin{array}{l}0.447^{* *} \\
(0.141)\end{array}$ \\
\hline Random $n$ th-round 3 & $\begin{array}{c}-1.055^{* *} \\
(0.131)\end{array}$ & $\begin{array}{c}-2.032^{* *} \\
(0.349)\end{array}$ & $\begin{array}{l}0.468^{* *} \\
(0.140)\end{array}$ \\
\hline Random $n$ th-round 4 & $\begin{array}{c}-1.153^{* *} \\
(0.131)\end{array}$ & $\begin{array}{l}-2.019^{* *} \\
(0.347)\end{array}$ & $\begin{array}{r}0.332^{*} \\
(0.140)\end{array}$ \\
\hline Random $n$ th-round 5 & $\begin{array}{c}-1.035^{* *} \\
(0.131)\end{array}$ & $\begin{array}{c}-1.953^{* *} \\
(0.346)\end{array}$ & $\begin{array}{l}0.390^{* *} \\
(0.140)\end{array}$ \\
\hline 2nd price-round 1 & $\begin{array}{c}-1.215^{* *} \\
(0.121)\end{array}$ & $\begin{array}{l}-1.105^{* *} \\
(0.274)\end{array}$ & $\begin{array}{c}-0.036 \\
(0.778)\end{array}$ \\
\hline 2nd price-round 2 & $\begin{array}{c}-0.539^{* *} \\
(0.121)\end{array}$ & $\begin{array}{c}-0.489 \\
(0.273)\end{array}$ & $\begin{array}{c}0.123 \\
(0.128)\end{array}$ \\
\hline 2nd price-round 3 & $\begin{array}{r}-0.300^{*} \\
(0.121)\end{array}$ & $\begin{array}{c}0.214 \\
(0.272)\end{array}$ & $\begin{array}{c}0.083 \\
(0.128)\end{array}$ \\
\hline 2 nd price-round 4 & $\begin{array}{c}-0.125 \\
(0.121)\end{array}$ & $\begin{array}{c}-0.001 \\
(0.274)\end{array}$ & $\begin{array}{c}0.049 \\
(0.128)\end{array}$ \\
\hline Gender & $\begin{array}{c}-0.576^{* *} \\
(0.078)\end{array}$ & $\begin{array}{l}0.662^{* *} \\
(0.237)\end{array}$ & $\begin{array}{c}-0.292^{* *} \\
(0.081)\end{array}$ \\
\hline Age & $\begin{array}{c}-0.035^{* *} \\
(0.004)\end{array}$ & $\begin{array}{r}0.017^{*} \\
(0.008)\end{array}$ & $\begin{array}{c}-0.007 \\
(0.004)\end{array}$ \\
\hline Education & $\begin{array}{l}0.210^{* *} \\
(0.074)\end{array}$ & $\begin{array}{c}-1.357^{* *} \\
(0.202)\end{array}$ & $\begin{array}{c}-0.269^{* *} \\
(0.084)\end{array}$ \\
\hline Income & $\begin{array}{l}0.139^{* *} \\
(0.015)\end{array}$ & $\begin{array}{l}0.045^{* *} \\
(0.027)\end{array}$ & $\begin{array}{l}0.039^{* *} \\
(0.015)\end{array}$ \\
\hline Student & $\begin{array}{l}-1.008^{* *} \\
(0.088)\end{array}$ & $\begin{array}{r}-0.623^{*} \\
(0.286)\end{array}$ & $\begin{array}{c}-0.427^{* *} \\
(0.100)\end{array}$ \\
\hline Log likelihood & -3194.75 & -2420.40 & -2176.49 \\
\hline Number of observations & 1995 & 1436 & 1596 \\
\hline
\end{tabular}

$*$ and ${ }^{* *}$ represent 0.05 and 0.01 levels of statistical significance, respectively.

a Numbers in parentheses are standard errors.

auction bids in excess of the BDM and English bids in latter bidding rounds.

\section{Test for Reference-Dependent Preferences}

Table 7 reports random effects tobit models designed to test whether the steak endowment affected valuations. Because the presence or absence of reference-dependent preferences could depend on the auction mechanism, we report separate models for each auction institution. The first column of results suggests the endowment significantly influenced second price auction bids. The sign of the coefficient, 
Table 7. Effect of Endowment on WTP: Random Effects Tobit Estimates

\begin{tabular}{|c|c|c|c|c|}
\hline \multirow[b]{2}{*}{ Variable } & \multicolumn{4}{|c|}{ Models } \\
\hline & 2nd Price & $\begin{array}{l}\text { Random } \\
n \text {th Price }\end{array}$ & English & BDM \\
\hline Constant & $\begin{array}{c}-0.826 \\
(0.483)^{\mathrm{a}}\end{array}$ & $\begin{array}{c}1.987^{* *} \\
(0.174)\end{array}$ & $\begin{array}{c}1.262 \\
(0.802)\end{array}$ & $\begin{array}{c}1.671 \\
(1.947)\end{array}$ \\
\hline Natural & $\begin{array}{c}-0.678^{* *} \\
(0.170)\end{array}$ & $\begin{array}{c}-0.415^{* *} \\
(0.077)\end{array}$ & $\begin{array}{c}-0.200 \\
(0.266)\end{array}$ & $\begin{array}{r}-1.019^{*} \\
(0.506)\end{array}$ \\
\hline Choice & $\begin{array}{c}0.699^{* *} \\
(0.163)\end{array}$ & $\begin{array}{c}0.727^{* *} \\
(0.072)\end{array}$ & $\begin{array}{l}1.175^{* *} \\
(0.263)\end{array}$ & $\begin{array}{l}1.110 \\
(0.654)\end{array}$ \\
\hline Certified Angus Beef & $\begin{array}{l}1.526^{* *} \\
(0.162)\end{array}$ & $\begin{array}{l}1.109^{* *} \\
(0.072)\end{array}$ & $\begin{array}{l}1.950^{* *} \\
(0.276)\end{array}$ & $\begin{array}{l}1.770^{* *} \\
(0.583)\end{array}$ \\
\hline Endowment treatment ${ }^{\mathrm{b}}$ & $\begin{array}{l}1.416^{* *} \\
(0.237)\end{array}$ & $\begin{array}{c}-0.949^{* *} \\
(0.072)\end{array}$ & $\begin{array}{c}-0.446 \\
(0.389)\end{array}$ & $\begin{array}{c}-0.052 \\
(0.804)\end{array}$ \\
\hline Round 1 & $\begin{array}{c}-0.552^{* *} \\
(0.185)\end{array}$ & $\begin{array}{c}-0.002 \\
(0.081)\end{array}$ & - & - \\
\hline Round 2 & $\begin{array}{c}-0.136 \\
(0.184)\end{array}$ & $\begin{array}{c}-0.029 \\
(0.081)\end{array}$ & - & - \\
\hline Round 3 & $\begin{array}{c}0.163 \\
(0.184)\end{array}$ & $\begin{array}{c}0.009 \\
(0.081)\end{array}$ & - & - \\
\hline Round 4 & $\begin{array}{c}0.033 \\
(0.185)\end{array}$ & $\begin{array}{c}-0.048 \\
(0.082)\end{array}$ & - & - \\
\hline Gender & $\begin{array}{l}1.113^{* *} \\
(0.316)\end{array}$ & $\begin{array}{c}-0.631^{* *} \\
(0.072)\end{array}$ & $\begin{array}{c}0.131 \\
(0.357)\end{array}$ & $\begin{array}{c}-2.066^{* *} \\
(0.703)\end{array}$ \\
\hline Age & $\begin{array}{r}0.025^{*} \\
(0.012)\end{array}$ & $\begin{array}{c}-0.022^{* *} \\
(0.003)\end{array}$ & $\begin{array}{c}-0.006 \\
(0.017)\end{array}$ & $\begin{array}{r}-0.005 \\
(0.036)\end{array}$ \\
\hline Education & $\begin{array}{c}-0.687^{* *} \\
(0.249)\end{array}$ & $\begin{array}{c}0.099 \\
(0.066)\end{array}$ & $\begin{array}{c}-0.350 \\
(0.404)\end{array}$ & $\begin{array}{c}0.144 \\
(0.701)\end{array}$ \\
\hline Income & $\begin{array}{c}0.176 \\
(0.036)\end{array}$ & $\begin{array}{c}0.017 \\
(0.012)\end{array}$ & $\begin{array}{c}-0.031 \\
(0.067)\end{array}$ & $\begin{array}{c}0.001 \\
(0.121)\end{array}$ \\
\hline Student & $\begin{array}{c}0.072 \\
(0.327)\end{array}$ & $\begin{array}{c}-0.459^{* *} \\
(0.094)\end{array}$ & $\begin{array}{c}-0.268 \\
(0.490)\end{array}$ & $\begin{array}{r}-1.039 \\
(1.217)\end{array}$ \\
\hline Log likelihood & -2394.78 & -1445.84 & -316.0 & -354.7 \\
\hline Number of observations & 1320 & 1280 & 212 & 220 \\
\hline
\end{tabular}

Note: Dependent variable: $\mathrm{WTP}_{\mathrm{A} i}$ for Endowment treatment and $\mathrm{WTP}_{i}-\mathrm{WTP}_{\mathrm{A}}$ for the No Endowment treatment. $*$ and $* *$ represent 0.05 and 0.01 levels of statistical significance, respectively.

${ }^{a}$ Numbers in parentheses are standard errors.

${ }^{\mathrm{b}}$ Variable $=1$ if WTP from Endowment treatment and 0 if WTP from No Endowment treatment.

however, suggests a counterintuitive result-a "reverse endowment effect." This finding suggests individuals in the second price auction valued the generic steak less when it was in their possession as opposed to when they were simply bidding to obtain it. Although this result is somewhat counterintuitive, it is not altogether inconsistent with previous research. For example, Knetsch, Tang, and Thaler found that after the first three bidding rounds of a second price auction, willingness-to-accept fell below WTP for the remaining bidding rounds of the experiment, a result consistent with a reverse endowment effect. Consistent with this finding, if we segregate our tests for the endowment effect by round (as opposed to one aggregate effect), we find that the endowment effect becomes more pronounced as auction round increases.
Results for the random $n$th price auction are more consistent with the traditional lossaversion theory. For the random $n$th price auction, subjects valued the generic steak more highly when it was in their possession as compared to when they were simply bidding to obtain it. For the English and BDM mechanisms, the endowment effect was negative, but not statistically significant.

Although the effect of the steak endowment was not consistent across auction mechanism, this procedural choice can have significant influences on bids. For the random $n$th price auction, one would tend to underestimate the value of a novel good or attribute if an endowment were given relative to the case where no endowment were provided. The magnitude of the coefficients on the endowment effects are relatively large- the same magnitude as 
the dummy variables for steak type, suggesting that the endowment effect can have important economic significance.

\section{Effect of Number of Goods}

Table 8 reports the final random effects tobit models testing whether subjects' valuations were influenced by the number of goods included in the experiment. Because we randomly drew a binding steak in each treatment, subjects' bids should not be influenced by the number of goods auctioned, assuming subjects' expected utility is linear in probabilities. Results in table 8 are only partially supportive of this assumption. The first column in table 8 indicates that auction bids were significantly greater when all five steaks were auctioned versus the case where only the generic and guaran-

Table 8. Effect of Number of Goods on WTP: Random Effects Tobit Estimates

\begin{tabular}{lcc}
\hline Variable & & $\begin{array}{c}\text { Implied } \\
\text { Cull Bids }\end{array}$ \\
\hline Differences \\
Guaranteed tender & $3.011^{* *}$ & -0.411 \\
& $(0.272)^{\mathrm{c}}$ & $(0.329)$ \\
Five goods & $0.850^{* *}$ & - \\
& $(0.086)$ & \\
Round 1 & $0.516^{*}$ & 0.045 \\
& $(0.144)$ & $(0.147)$ \\
Round 2 & $-1.100^{* *}$ & 0.111 \\
& $(0.136)$ & $(0.142)$ \\
Round 3 & $-0.603^{* *}$ & 0.149 \\
& $(0.136)$ & $(0.142)$ \\
Round 4 & $-0.460^{* *}$ & 0.143 \\
& $(0.136)$ & $(0.142)$ \\
Gender & -0.079 & 0.187 \\
& $(0.136)$ & $(0.142)$ \\
Age & $-0.399^{* *}$ & $0.572^{* *}$ \\
& $(0.138)$ & $(0.154)$ \\
Education & $0.024^{* *}$ & $0.017^{* *}$ \\
Income & $(0.006)$ & $(0.006)$ \\
& $-0.474^{* *}$ & $-0.355^{* *}$ \\
Student & $(0.139)$ & $(0.141)$ \\
Log likelihood & $0.074^{*}$ & -0.022 \\
Number of & $(0.035)$ & $(0.027)$ \\
observations & $-1.534^{* *}$ & $-0.953^{* *}$ \\
\hline & $(0.154)$ & $(0.216)$ \\
& -842.59 & -309.05 \\
& 550 & 275 \\
& 550 & 275 \\
\hline
\end{tabular}

$*$ and ${ }^{* *}$ represent 0.05 and 0.01 levels of statistical significance, respectively.

${ }^{a}$ The dependent variable consists of auction bids for the generic and guaranteed tender steaks.

${ }^{\mathrm{b}}$ The dependent variable is $\mathrm{WTP}_{\text {guaranteed tender }}-\mathrm{WTP}_{\text {generic }}$.

${ }^{\mathrm{c}}$ Numbers in parentheses are standard errors.

${ }^{\mathrm{d}}$ Variable $=1$ if WTP from treatment where five goods were valued and 0 if WTP from treatment where two goods were valued teed tender steaks were auctioned. Although the result indicates a phenomenon similar to that observed by List (2002), the magnitude of the coefficient is relatively small in comparison to the Guaranteed Tender dummy variable and dummy variables identifying auction round. That is, the result may not be economically significant. Further, it is worth noting that, in contrast to the results previously reported in tables 6 and 7, the statistical significance of the Five Goods variable is sensitive to inclusion/exclusion of the demographic variables such as Student which may indicate problems with multicolliniearity and the need to conduct this test with a larger sample of individuals. The second column in table 8 reports regression results pertaining to the test of whether the number of goods auctioned affected the difference in value between the generic and guaranteed tender steak. Results indicate that the differences in subjects' bids for the generic and guaranteed tender steaks were uninfluenced by whether the natural, Choice, and CAB steaks were present.

\section{Conclusions}

Despite increased use of experimental auctions to estimate the value of nonmarket goods, a number of issues remain unresolved. In particular, a myriad of different procedures are being employed without formal consideration of how the procedure might affect results. This study analyzed the effect of several procedural issues on valuations from experimental auctions.

Choice of auction institution significantly (both statistically and economically) influenced bids. Although first round second price auction bids were similar to those produce by other mechanisms, bids from rounds 2 and higher in second price auction were significantly greater than bids from the other mechanisms. The second price auction generated bids from $20 \%$ to $300 \%$ greater than bids from random $n$th price, BDM, and English auctions. Relatively high bids in second price auctions may be due to a variety of factors such as the failure to incorporate the cost of overbidding, subjects deriving utility from being the sole winner, or increased bids due to bidder affiliation and posting of prices over multiple rounds. Random $n$th price bids from all five bidding rounds were significantly (statistically and economically) lower than BDM and English bids 
when subjects were provided an endowment. Interestingly, the BDM and English price auctions generated statistically equivalent bids in both the Endowment and No Endowment treatments. The BDM and English auctions differ vastly in terms of market involvement and feedback. In a BDM auction, each subject essentially bids against a random number generator, with no competition or feedback from other subjects. In contrast, the English auction is structured so every participant is keenly aware of other bidders and the market price.

Endowing subjects with a good significantly influenced valuations. Consistent with the lossaversion theory, providing subjects with an endowment decreased the relative value subjects placed on nonendowed goods in the random $n$th price auction. In contrast, we observed the opposite case for the second price auctionsubjects valued the generic steak less when it was in their possession than when they were bidding on it. It is unclear why the latter result was obtained, but it is consistent with results reported by Knetsch, Tang, and Thaler in the final three bidding rounds of their second price auctions, indicating the result may partially be due to the dynamics of the second price auction. Providing an endowment did not significant affect bids in English or BDM auctions. Perhaps one partial explanation why reference-dependent preferences existed for the random $n$th price and second price auction, but not for the BDM or English is that both the English and BDM were singleround, whereas the second and random $n$th were multiple-round auctions. Indeed, if we segregate our tests for the endowment effect by round for the second price auction, we find that the effect is more pronounced in round 5 than in round 1 . Future research might focus on identifying fundamental differences in elicitation mechanisms and auction procedure that cause individuals to alter the way they view endowments.

The primary message from this study is that valuations are not generally invariant to procedural change. Choice of auction mechanism and whether to endow subjects with a good can influence results and subsequent forecasts and recommendations. For most researchers, it will be infeasible to carry out all the comparisons conducted in this study and one is inescapably left to choose one particular auction mechanism and one particular procedure. Although this constraint is restrictive, this study provides some insight as to how results might vary if an alternative choice had been made.

\section{[Received November 2002; accepted July 2003.]}

\section{References}

Becker, G.M., M.H. DeGroot, and J. Marschak. "Measuring Utility by a Single-Response Sequential Method." Behavioural Science 9(1964):226-32.

Buzby, J.C., J.A. Fox, R.C. Ready, and S.R. Crutchfield. "Measuring Consumer Benefits of Food Safety Risk Reductions." Journal of Agricultural and Applied Economics 10(1998):69-82.

Coppinger, V.M., V.L. Smith, and J.A. Titus. "Incentives and Behavior in English, Dutch, and Sealed-Bid Auctions." Economic Inquiry 43(1980):1-22.

Cummings, R.G., G.W. Harrison, and E.E. Rutström. "Homegrown Values and Hypothetical Surveys: Is the Dichotomous Choice Approach Incentive-Compatible?" American Economic Review 85(1995):260-66.

Fox, J.A. "Determinants of Consumer Acceptability of Bovine Somatotropin." Review of Agricultural Economics 17(1995):51-62.

Fox, J.A., J.F. Shogren, D.J. Hayes, and J.B. Kliebenstein. "CVM-X: Calibrating Contingent Values with Experimental Auction Markets." American Journal of Agricultural Economics 80(1998):455-65.

Greene, W.H. LIMDEP Version 7.0 User's Manual. Econometric Software, Plainview, NY, 1998.

Hayes, D.J., J.F. Shogren, S.U. Shin, and J.B. Kliebenstein. "Valuing Food Safety in Experimental Auction Markets." American Journal of Agricultural Economics 77(1995):40-53.

Hoffman, E., D. Menkhaus, D. Chakravarit, R. Field, and G. Whipple. "Using Laboratory Experimental Auctions in Marketing Research: A Case Study of New Packaging for Fresh Beef." Marketing Science 12(1993):318-38.

Irwin, J.R., G.H. McClelland, M. McKee, W.D. Schulze, and N.E. Norden. "Payoff Dominance vs. Cognitive Transparency in Decision Making." Economic Inquiry 36(1998):272-85.

Kagel, J.H., R.M. Harstad, and D. Levin. "Information Impact and Allocation Rules in Auctions with Affiliated Private Values: A Laboratory Study." Econometrica 55(1987):1275-304.

Kagel, J.H., and D. Levin. "Independent Private Value Auctions: Bidder Behavior in First- Second-, and Third Price Auctions with 
Varying Numbers of Bidders." Economic Journal 103(1993):868-79.

Knetsch, J.L., F.F. Tang, and R.H. Thaler. "The Endowment Effect and Repeated Market Trials: Is the Vickrey Auction Demand Revealing?" Experimental Economics 4(2001):25769.

List, J.A. "Preference Reversals of a Different Kind: The 'More is Less' Phenomenon." American Economic Review 92(2002):1636-43.

List, J.A. "Using Random $n$th Price Auctions to Value Non-Market Goods and Services." Journal of Regulatory Economics 23(2003):193205.

List, J.A., and D. Lucking-Reiley. "Demand Reduction in Multiunit Auctions: Evidence from a Sports Card Field Experiment." American Economic Review 90(2000):961-72.

List, J.A., and J.F. Shogren. "Calibration of the Differences Between Actual and Hypothetical Valuations in a Field Experiment." Journal of Economic Behavior and Organization 37(1998):193-205.

- "Price Information and Bidding Behavior in Repeated Second-Price Auctions." American Journal of Agricultural Economics 81(1999):942-49.

Lucking-Reiley, D. "Using Field Experiments to Test Equivalence Between Auction Formats: Magic on the Internet." American Economic Review 89(1999):1063-80.

Lusk, J.L. "Branded Beef. Is It What's For Dinner?" Choices 2nd Quarter(2001):27-30.

Lusk, J.L., M.S. Daniel, C.L. Lusk, and D.R. Mark. "Alternative Calibration and Auction Institutions for Predicting Consumer Willingness to Pay for Non-Genetically Modified Corn Chips." Journal of Agricultural and Resource Economics 26(2001a):40-57.

Lusk, J.L., J.A. Fox, T.C. Schroeder, J. Mintert, and M. Koohmaraie. "In-Store Valuation of Steak Tenderness." American Journal of Agricultural Economics 83(2001b):539-50.

Lusk, J.L., J. Roosen, and J.A. Fox. "Demand for Beef from Cattle Administered Growth Hormones or Fed Genetically Modified Corn: A Comparison of Consumers in France, Germany, the United Kingdom, and the United States." American Journal of Agricultural Economics 85(2003):16-29.

Melton, B.E., W.E. Huffman, J.F. Shogren, and J.A. Fox. "Consumer Preferences for Fresh Food Items with Multiple Quality Attributes: Evi- dence from an Experimental Auction of Pork Chops." American Journal of Agricultural Economics 78(1996):916-23.

Milgrom, P.R., and R.J. Weber. "A Theory of Auctions and Competitive Bidding." Econometrica 50(1982):1089-122.

Roosen, J., D.A. Hennessy, J.A. Fox, and A. Schreiber. "Consumers' Valuation of Insecticide Use Restrictions: An Application to Apples." Journal of Agricultural and Resource Economics 23(1998):367-84.

Rutström, E.E. "Home-Grown Values and Incentive Compatible Auction Design." International Journal of Game Theory 27(1998):42741.

Simonson, I. "Choice Based on Reasons: The Case of Attraction and Compromise Effects." Journal of Consumer Research 16(1989):15874.

Simonson, I., and A. Tyversky. "Choice in Context: Tradeoff Contrast and Extremeness Aversion." Journal of Marketing Research 29(1992):28195.

Shogren, J.F., S. Cho, C. Koo, J. List, C. Park, P. Polo, and R. Wilhelmi. "Auction mechanisms and the measurement of WTP and WTA." Resource and Energy Economics 23(2001a):97-109.

Shogren, J.F., M. Margolis, C. Koo, and J.A. List. "A Random $n$ th-Price Auction." Journal of Economic Behavior and Organization 46(2001b):409-21.

Shogren, J.F., J.A. Fox, D.J. Hayes, and J.B. Kliebenstein. "Bid Sensitivity and the Structure of the Vickrey Auction." American Journal of Agricultural Economics 76(1994):1089-95.

Shogren, J.F., D.J. Hayes, J.A. Fox, and T.L. Cherry. "Auctions 101: Lessons from a Decade in the Lab." Choices (Spring 2002):16-21.

Shogren, J.F., J.A. List, and D.J. Hayes. "Preference Learning in Consecutive Experimental Auctions." American Journal of Agricultural Economics 82(2000):1016-21.

Tversky, A., and Kahneman, D. "Loss Aversion in Riskless Choice: A Reference-Dependent Model." Quarterly Journal of Economics 106(1991):1039-61.

Vickrey, W. "Counterspeculation, Auctions and Competitive Sealed Tenders." Journal of Finance 16(1961):8-37.

Wertenbroch, K., and B. Skiera. "Measuring Consumers' Willingness to Pay at the Point of Purchase." Journal of Marketing Research 39(2002):228-41. 